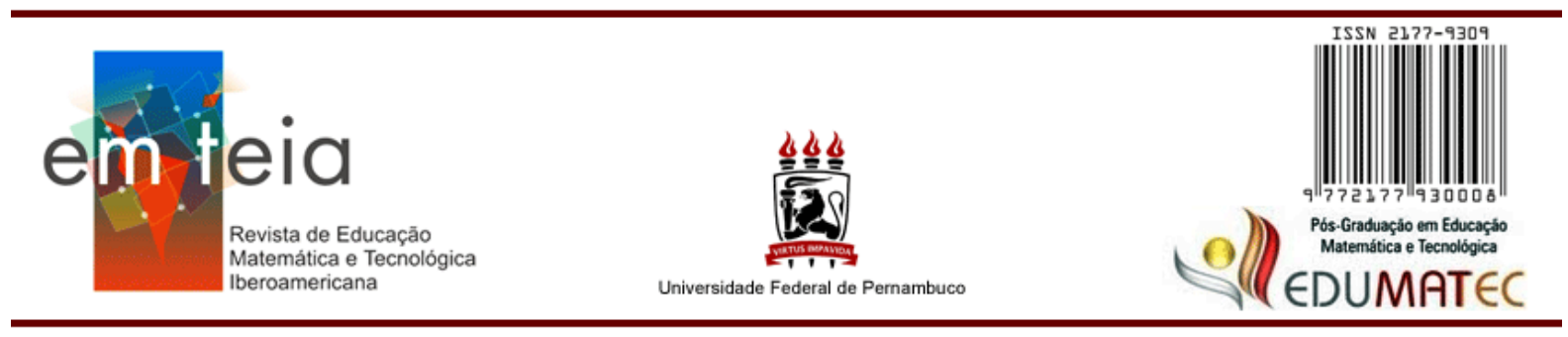

REFLEXÕES SOBRE EDUCAÇÃO FINANCEIRA ESCOLAR:

o que é discutido em cursos de formação de professores dos anos iniciais e como ocorre na prática? ${ }^{1}$

Reflections on School Financial Education:

what is discussed in teacher training courses in the early years and how does it happen in practice?

Adryanne Maria Rodrigues Barreto de Assis

Doutoranda em Educação Matemática e Tecnológica Universidade Federal de Pernambuco - Pernambuco - Brasil adryanne@gmail.com https://orcid.org/0000-0002-3561-6513

Laís Thalita Bezerra dos Santos

Doutoranda em Educação Matemática e Tecnológica Universidade Federal de Pernambuco - Pernambuco - Brasil laisthalita@hotmail.com http://orcid.org/0000-0001-5724-0556?lang=en

Anaelize dos Anjos Oliveira

Doutoranda em Educação Matemática e Tecnológica Universidade Federal de Pernambuco - Pernambuco - Brasil Anaelizeoliveira89@gmail.com https://orcid.org/0000-0001-6183-6344

Cristiane Azevêdo dos Santos Pessoa

Doutora em Educação

Universidade Federal de Pernambuco - Pernambuco - Brasil cristianepessoa74@gmail.com http://orcid.org/0000-0002-5434-8999

\title{
Resumo
}

No presente artigo, objetivamos investigar se e como a Educação Financeira (EF) está sendo discutida em cursos de formação inicial de professores e analisar como professores desenvolvem o trabalho com tal temática em salas de aula. Como aporte teórico, utilizamos a Educação Matemática Crítica discutida

\footnotetext{
${ }^{1}$ Resultados parciais desse estudo foram publicados no XIX Encontro Nacional de Educação Matemática - XIX ENEM e no estudo de dissertação de Oliveira (2017). Link para acesso: https://repositorio.ufpe.br/bitstream/123456789/32214/1/DISSERTA $\%$ C3\%87\%C3\%83O $\% 20$ Anaelize $\% 20 \mathrm{dos}$ $\% 20$ Anjos $\% 20$ Oliveira.pdf .
} 
por Ole Skovsmose, defendendo a ideia de uma matemática que atenda às necessidades sociais. Como método, aplicamos um questionário disponibilizado no Google Formulários para ser respondido online por estudantes em processo formativo no Ensino Superior, no curso de Pedagogia, e observamos oito aulas de Educação Financeira de duas professoras dos $4^{\circ}$ e $5^{\circ}$ anos de uma escola da rede privada, utilizando como recurso gravações em áudios e entrevistas após as aulas. Observamos que, apesar de a maioria dos estudantes de Pedagogia participantes da pesquisa não conhecerem a Estratégia Nacional de Educação Financeira (Enef), não possuírem uma maior orientação acerca do uso do dinheiro e não terem tido contato de forma sistemática, durante sua formação, com a Educação Financeira, acreditam ser necessária a inclusão dessa discussão tanto em salas de aula do curso de Pedagogia, como no ambiente escolar. Em relação às professoras observadas, ainda que sem uma formação inicial sobre o tema, desenvolvem discussões interessantes sobre a EF em sala de aula. Como considerações, defendemos a inserção de discussões acerca da Educação Financeira nos cursos de formação de professores dos anos iniciais.

Palavras-Chave: Educação financeira. Formação inicial de professores. Matemática. Prática docente.

\begin{abstract}
In this article, we aim to investigate whether and how Financial Education is being discussed in initial teacher training courses and to analyze how teachers develop work with this theme in classrooms. As a theoretical contribution, we use the Critical Mathematics Education discussed by Ole Skovsmose, defending the idea of a mathematics that meets social needs. As a method, we applied a questionnaire made available on Google Forms to be answered online by students in a training process in Higher Education, in the Pedagogy course, and we observed eight Financial Education classes from two teachers from the 4th and 5th years of a private school, using audio recordings and interviews after classes as a resource. We observed that, although the majority of Pedagogy students participating in the research do not know the National Strategy for Financial Education (Enef), they do not have greater guidance about the use of money and have not had systematic contact, during their training, with Financial Education, believe it is necessary to include this discussion both in classrooms of the Pedagogy course, as well as in the school environment. Regarding the observed teachers, even without initial training on the topic, they develop interesting discussions about EF in the classroom. As considerations, we defend the inclusion of discussions about Financial Education in teacher training courses in the early years.
\end{abstract}

Keywords: financial education. Initial teacher training. Mathematics. Teaching practice.

\title{
Introdução
}

O presente estudo surgiu a partir do interesse por investigar se e como a Educação Financeira $(\mathrm{EF})$ está sendo discutida em cursos de formação inicial de professores e analisar como professores desenvolvem trabalho com tal temática em salas de aula.

A EF vem, desde 2010, adquirindo maior espaço nas discussões relacionadas à educação e, com a inserção da temática na Base Nacional Comum Curricular - BNCC (BRASIL, 2017) como um tema transversal, integrador e contemporâneo, a cobrança pelo trabalho com a EF nas 
escolas se tornou ainda mais forte, necessitando, desta forma, que os professores estejam preparados e formados para tal trabalho e, assim, surgiu o interesse por investigar se e como a discussão sobre esta temática está ocorrendo nas salas de aula do Ensino Superior e na prática docente nos anos iniciais do Ensino Fundamental.

É importante lembrar que a EF começou a ganhar um maior espaço no cenário educacional a partir da criação, em 2010, da Estratégia Nacional de Educação Financeira (Enef), através do Decreto no 7.397 de 2010 (BRASIL, 2010), que estabeleceu no Brasil uma série de ações relacionadas à EF. Uma das linhas de trabalho da ENEF é a escola básica. Como supracitado, hoje, a EF já foi inserida na BNCC (BRASIL, 2017) e já é amplamente discutida por pesquisadores de diversas regiões do país.

A Enef, em parceria com o Ministério da Educação - MEC e com outras instituições que compõem esta estratégia, implementou um material para ser trabalhado em escolas brasileiras. A preocupação existente, nesse sentido, como discutido por Campos (2012), Silva e Powell (2013) e Santos (2017), é a de que na Enef há a influência de diversas instituições privadas, o que nos leva a reafirmar o questionamento apresentado por tais pesquisadores: que interesse instituições privadas possuem de que indivíduos sejam formados criticamente para lidar com situações financeiras?

Aliada a essa preocupação, surge a necessidade latente de que os professores dos anos iniciais que estão em sala de aula e que receberam/receberão o material disponibilizado pelo MEC tenham consciência e criticidade para identificar, se assim houver, uma intenção diferente do que acreditamos ser importante no momento de discutir questões relacionadas à EF. Se os docentes não possuírem discernimento e compreensão suficientes para entender, de fato, o que está sendo proposto, podem reforçar com os alunos uma discussão que os leve a se tornarem, apenas, consumidores de produtos financeiros, não refletindo sobre questões essenciais relacionadas à EF e que ajudam no momento das tomadas de decisões ao longo da vida.

Deste modo, propomo-nos, no presente estudo, a investigar se e como a Educação Financeira está sendo discutida em cursos de formação inicial de professores e analisar como professores desenvolvem trabalho com tal temática em salas de aula. Neste sentido, buscamos identificar como a temática é abordada na formação inicial e, posteriormente, analisamos a prática docente acerca do trabalho com a EF. A seguir, apresentamos a revisão da literatura e a fundamentação teórica que subsidiaram a percepção sobre EF e a discussão sobre os dados que apresentamos no estudo. 


\section{Formação de professores que ensinam Matemática}

Cada vez mais surge a importância de debater e, se necessário, rever o processo formativo inicial dos professores que lecionam na Educação Básica, uma vez que há a necessidade de que tais professores estejam atentos às novas realidades. Com base nisso, Curi e Pires (2004) afirmam que é preciso repensar os cursos de formação de professores, especificamente os voltados para o ensino da Matemática. Entendemos, assim, que é importante repensar e ressignificar o fazer pedagógico, sendo tal processo, de acordo com Rocha (2011), ininterrupto, sistemático, organizado e complexo.

Ainda nesse contexto, Vasconcellos e Bittar (2007) reforçam que, no geral, o processo de formação docente apresenta falhas e lacunas em sua realização. De acordo com Nacarato (2000), os cursos de formação docente têm uma carga horária reduzida e, ao longo de seu desenvolvimento, pouco é o espaço para discussões com foco no ensino da Matemática. Sobre tal discussão, Cunha (2010) também alerta acerca desta realidade, enfatizando que, de 45 cursos de formação inicial em Pedagogia pesquisados no Brasil, as disciplinas destinadas à Matemática correspondem a cerca de $4 \%$ do total da carga horária de cada curso.

De acordo com Cunha (2010), é imprescindível que, durante a formação docente, aquele futuro professor desenvolva diferentes competências ao refletirem sobre o ensino da Matemática nos anos iniciais do Ensino Fundamental, dentre elas, domínio do conteúdo e domínio pedagógico do conteúdo. Além de Cunha (2010), outros autores também discorrem acerca dos saberes/conhecimentos/competências necessários que estão atrelados ao ensino da Matemática, como Ball, Thames e Phelps (2008) e Curi (2005).

Desta forma, considerando os estudos citados acima, entendemos que há a importância de um olhar mais aprofundado para a formação inicial dos professores que ensinam Matemática nos anos iniciais do Ensino Fundamental, havendo discussão sobre diferentes metodologias que estão relacionadas a esta área de ensino, como também sobre o que ensinar (COSTA; PINHEIRO; COSTA, 2016).

Sendo assim, conjecturamos ser necessária uma discussão mais profunda e ações específicas para melhorar o desenvolvimento e as discussões envolvendo a formação inicial e continuada de professores, no que tange aos conhecimentos específicos acerca da área da Matemática e sobre a EF particularmente, por ser uma temática nova para o trabalho de professores e por estar relacionada não apenas à Matemática, mas às diferentes áreas do conhecimento. 
A seguir, apresentamos, de forma específica, uma discussão sobre a formação de professores e a EF, temática discutida no presente estudo.

\section{Educação Financeira e a formação de professores}

Refletindo especificamente sobre a EF, consideramos importante explicitar, em princípio, a definição adotada acerca da temática no presente estudo.

Corroboramos Silva e Powell (2013, p. 13) que definem a EF como

um conjunto de informações através do qual os estudantes são introduzidos no universo do dinheiro e estimulados a produzir uma compreensão sobre finanças e economia, através de um processo de ensino, que os torne aptos a analisar, fazer julgamentos fundamentados, tomar decisões e ter posições críticas sobre questões financeiras que envolvam sua vida pessoal, familiar e da sociedade em que vivem.

Deste modo, percebemos a EF como uma discussão que pode instrumentalizar as pessoas para agirem criticamente diante das situações de consumo com as quais podem se deparar ao longo da vida. Consideramos importante ressaltar que a EF só terá esse potencial crítico na sociedade se forem discutidas temáticas que de fato tenham relação com a vida e com as questões de consumo com as quais os indivíduos lidam cotidianamente.

Uma vez que defendemos uma discussão crítica envolvendo a temática EF em sala de aula, pensamos ser necessário investigar se e como os estudantes estão sendo formados em cursos de graduação para lidar com a temática. Além disso, é importante observar a formação continuada dos professores. Dizemos isso porque a temática EF começou a ser mais discutida a partir de 2010, como já mencionamos, a partir da inserção da Enef (2010), e é preciso pensar na formação, também, dos professores formados anteriormente a essa data.

Teixeira (2017) realizou entrevistas semiestruturadas com cinco professores do $5^{\circ}$ ano da rede municipal do Estado de São Paulo, observando as facilidades/dificuldades existentes quando eram resolvidos problemas envolvendo a EF. A pesquisadora aponta como um de seus resultados a percepção de que as docentes analisadas fazem uma associação "entre a Educação Financeira e o Sistema Monetário, o que nos mostra a necessidade de formação sobre o assunto" (TEIXEIRA, 2017, p. 115). A pesquisadora aponta, ainda, a necessidade de

criação de formações continuadas que abordem o tema Educação Financeira nas escolas da Rede Municipal, bem como encontros específicos sobre conteúdos matemáticos que sirvam como "propulsores" e ferramentas úteis para o desenvolvimento de princípios financeiros, para que juntamente possam oferecer estratégias diferenciadas de ensino e recursos didáticos que, 
de fato, auxiliem os professores em suas práticas pedagógicas (TEIXEIRA, 2017, p. 116).

Silva (2018), por sua vez, analisou como professores dos anos iniciais do Ensino Fundamental colocam em prática atividades de EF presentes em livros didáticos de Matemática dos anos iniciais. Participaram do estudo oito professores de escolas municipais da cidade de Garanhuns - PE. Corroborando o que é exposto por Teixeira (2017), Silva (2018) discute que "a maioria dos professores participantes da pesquisa apresenta escasso conhecimento sobre o que é Educação Financeira, reduzindo o seu significado, sobretudo ao trabalho com o sistema monetário" (p. 9).

Deste modo, percebemos que professores dos anos iniciais do Ensino Fundamental não apresentam uma maior compreensão sobre o que é a EF e como trabalhá-la em sala de aula, confundindo-a com o trabalho com o sistema monetário, por exemplo.

Com base nessas discussões, ressaltamos a importância do presente estudo, que objetiva investigar se e como a EF está sendo discutida em cursos de formação inicial de professores e analisar como professores desenvolvem trabalho com tal temática em salas de aula.

A Educação Matemática Crítica, que discute a Matemática e a sua utilização nas práticas sociais, se constitui, além de teoria que nos embasa, uma possível forma de trabalho que estimula reflexão, crítica e análise da Matemática a partir de uma perspectiva social, política, econômica e cultural, objetivando um trabalho com a Matemática como ferramenta de investigação e estímulo à autonomia intelectual.

É a partir da EMC que se começa a pensar em um uso da Matemática para as práticas sociais, com as ideias de Ole Skovsmose, um dinamarquês que vem desenvolvendo uma série de estudos no Brasil.

Skovsmose (2014) discute o modo distante da realidade dos estudantes como acontece, atualmente, o ensino da Matemática. Os discentes são colocados diante de uma infinidade de exercícios que pouco auxiliam em suas vidas e que pouco têm relação com situações com as quais eles lidarão em seu desenvolvimento.

Com a EF em uma perspectiva crítica, os professores, em sala de aula, desenvolverão com os estudantes discussões que poderão auxiliar, de fato, em situações do cotidiano. Haverá, assim, uma quebra com o paradigma do exercício, no qual os estudantes são colocados diante de situações e o único objetivo é chegar ao resultado correto, sem haver reflexão ou utilização, de fato, no cotidiano.

Adiante, apresentamos o método utilizado no presente estudo. 


\section{Percurso metodológico}

O presente estudo trata-se do recorte de duas pesquisas: Oliveira (2017) investigou como o trabalho com a Educação Financeira Escolar (EFE) está sendo abordado nos anos iniciais do Ensino Fundamental, e Santos e Assis (2019) buscaram verificar se estudantes do curso de Pedagogia investigados abordaram a temática EF durante seu processo formativo e se/como professores visualizam um possível trabalho com tal temática em salas de aula.

Consideramos ser importante destacar que embora os sujeitos analisados sejam de estudos distintos (discentes graduandos em Pedagogia e docentes), os resultados apresentados na discussão do presente estudo nos permitem ter uma visão do que podemos encontrar, ou não, na formação inicial e na prática pedagógica para o trabalho/discussão acerca da EF.

Participaram da pesquisa 19 estudantes do Ensino Superior em Pedagogia, sendo 10 da rede pública e nove da rede privada de ensino, todos já tendo cursado pelo menos a metade do curso. Contamos também com a participação de duas professoras do $4^{\circ}$ e do $5^{\circ}$ ano de uma escola da rede privada, que desenvolveram um trabalho sistemático com a EF.

Como instrumento de coleta, foi elaborado e disponibilizado um questionário por meio da ferramenta Formulários, do Google, para o levantamento dos dados acerca da discussão de EF nos cursos de formação inicial. Foram também realizadas oito observações de aulas de EF em uma turma do $4^{\circ}$ e em uma turma do $5^{\circ}$ ano (quatro aulas em cada ano indicado) de uma escola privada de Recife-PE, com o recurso de gravações em áudio e entrevistas com as professoras investigadas, após as aulas.

Com a finalidade de compreender melhor a prática das professoras, questionamos: a) Conseguiu atingir o objetivo com a aula? b) O que você gostaria de desenvolver a partir destes momentos (fazer referência ao que foi trabalhado)? c) Como você pretende dar continuidade à temática? d) Como você avalia esta aula? Faria algo diferente? Se sim, o quê?

A seguir, apresentamos o questionário que foi disponibilizado no Formulários Google para os estudantes de Pedagogia.

1. Nome; 2. Endereço de e-mail; 3. Instituição em que estuda. Opções: privada; pública; 4. Período do curso de Pedagogia; 5. Já cursou as disciplinas obrigatórias de Matemática no Curso de Pedagogia? 6. Como você ganha o seu dinheiro? Opções: trabalho; mesada; não tenho renda; outros; 7. Caso ganhe dinheiro de alguma forma, o que faz com ele? Opções: gasta todo durante o mês; guarda alguma quantia; 8. Se guarda dinheiro de alguma forma, onde guarda? 9. Como você aprendeu sobre seu modo de pensar acerca do uso do dinheiro? Opções: em casa; na escola; na faculdade; através da mídia; cursos específicos sobre organização financeira; outros; 10. Como você se sente a respeito dos seus conhecimentos para gerenciar seu dinheiro? Opções: Nada seguro (a) - Gostaria de possuir um nível muito melhor de Educação Financeira; Não muito seguro - Gostaria de saber um pouco mais sobre finanças; Razoavelmente seguro - Conheço a maioria das coisas que precisaria saber sobre o assunto; Muito seguro - Possuo conhecimentos bastante amplos sobre finanças; 11. Você lembra de ter tido alguma discussão no Ensino Superior sobre a temática Educação Financeira? Opções: sim; não; 12. Se sim, comente sobre o que foi discutido; 13. Se não, considerando a possibilidade de incluir uma discussão sobre Educação Financeira na grade 
curricular do seu curso, você considera isso: Opções: Muito importante; Com média importância; Com pouca importância; Sem importância; 14. Você conhece a Estratégia Nacional de Educação Financeira - ENEF, instituída pelo Decreto $n^{\circ} 7.397$ de 22 de dezembro de 2010, a qual tem a finalidade de promover a Educação Financeira para o fortalecimento da cidadania? Opções: sim; não; 15. Você considera importante discutir a Educação Financeira em salas de aula da Educação Infantil e/ou dos Anos Iniciais do Ensino Fundamental? Opções: sim; não; 16. Comente sobre a resposta anterior; 17. Você se considera apto para trabalhar a Educação Financeira em uma sala de aula da Educação Infantil ou do Ensino Fundamental 1? Opções: sim; não; 18. Caso a Educação Financeira fosse trabalhada em sala de aula dos Anos Iniciais, com qual(is) disciplina(s) você acredita que ela poderia se relacionar? ${ }^{2}$

A seguir, apresentamos e analisamos os resultados encontrados no estudo.

\section{Resultados e discussões}

\section{Formação inicial de estudantes de Pedagogia sobre Educação Financeira}

Iniciamos a discussão dos dados buscando responder ao nosso primeiro objetivo, de investigar se e como a EF está sendo discutida em cursos de formação inicial de professores. Foram pesquisados 19 estudantes do Ensino Superior em Pedagogia, sendo 10 da rede pública e nove da rede privada de ensino, todos já tendo cursado pelo menos a metade do curso.

Dentre esses, 16 afirmaram já haver cursado as disciplinas obrigatórias de Ensino da Matemática durante o curso e três não. Tal questionamento foi feito aos estudantes porque acreditamos na forte relação entre a EF e a Matemática, logo, ter cursado as disciplinas obrigatórias de Matemática poderia ser um dado relevante para as reflexões apresentadas pelo estudante no decorrer do questionário. Apesar disso, consideramos importante abarcar nas análises os demais estudantes, que não cursaram as disciplinas obrigatórias de Ensino da Matemática, mas que podem ter vivenciado outras discussões relacionando EF com outras áreas da educação. Dizemos isso porque, apesar de defendermos a forte relação e aproximação da EF com a Matemática, temos consciência acerca da possibilidade e da importância de discussão desta temática a partir de outras áreas. Quando se discute, por exemplo, sustentabilidade, na disciplina de Ciências, ou um texto que propõe a interpretação e discussão sobre a influência das propagandas, no âmbito da Língua Portuguesa, está sendo propiciada uma discussão sobre aspectos importantes que têm ampla relação com a EF. Campos (2012) e Santos (2017) corroboram essa discussão quando chamam a atenção para o fato de que, apesar de terem discutido, em seus estudos, a EF na perspectiva da Matemática, isso não significa que outros conteúdos/disciplinas não possam dialogar com a temática.

\footnotetext{
${ }^{2}$ As perguntas de número 6, 7, 8 e 9 foram retiradas do questionário aplicado por Pelicioly (2011). A pergunta de número 10 foi retirada do questionário aplicado por Campos e Kistemann Jr. (2015).
} 
No que se refere à pergunta “como você ganha dinheiro?”, 13 dos participantes afirmam trabalhar, quatro indicaram ter outra fonte de renda (assistência estudantil/bolsista, pensão e mesada) e dois declararam não possuir renda.

Desse modo, a maioria dos participantes possui renda. Além disso, acreditamos que os participantes que declararam não possuir renda também movimentam dinheiro de alguma forma. Logo, todos estão envolvidos em situações financeiras, uma vez que a sociedade em que estão inseridos é de consumo e as relações de compra e venda são frequentes.

A pergunta seguinte apresentada no questionário "Caso ganhe dinheiro de alguma forma, o que você faz com ele?" foi respondida por todos os participantes, o que valida a hipótese acima apresentada, de que, mesmo sem renda, todos movimentam valores financeiros mensalmente. Oito dos participantes afirmaram gastar todo o dinheiro durante o mês, enquanto os demais (11) indicaram guardar alguma quantia.

Dos que informam guardar alguma quantia, nove afirmaram ter o banco como local adequado para suas reservas financeiras; um participante apresentou o banco como uma possibilidade, mas mencionou também deixar alguma quantia em sua residência. Por fim, uma participante declarou "o que sobra do aluguel, contas e alimentação, eu guardo no meu armário, numa caixinha". Percebe-se, assim, que o banco vem sendo apresentado como principal local de reserva para aqueles que conseguem poupar alguma quantia no final do mês. Tal dado auxilia na reflexão de que mais da metade dos participantes, de alguma forma, se preocupam em guardar parte da quantia que recebem mensalmente. Poupar, de fato, é um ponto importante, visto que podem acontecer situações emergenciais em que os indivíduos precisarão recorrer às possíveis reservas existentes.

Apesar disso, salientamos, no presente estudo, que a EF vai além do poupar, principalmente se a visão for o "poupe hoje para comprar algo amanhã", uma vez que esta perspectiva reforça o consumismo vigente na sociedade atual.

Além disso, é preciso preocupar-se com a compreensão que tais indivíduos possuem sobre o papel dos bancos, uma vez que podem ser oferecidos produtos financeiros que eles considerem que são interessantes, mas que na verdade serão muito mais vantajosos para os bancos do que para eles próprios. Corroborando com tal discussão, Kassardjian (2013) explicita a compreensão de que a EF é um conceito muito mais amplo que o investimento do dinheiro ou a utilização de produtos financeiros.

Após esse primeiro bloco de perguntas, que possibilitou compreender, de modo geral, quem são os participantes do presente estudo, apresentaremos o bloco de questões seguintes, 
no qual buscamos compreender se/como tais indivíduos entendem temáticas que envolvem a EF, bem como a sua formação inicial no curso superior de Pedagogia.

A primeira pergunta deste bloco, "Como você aprendeu sobre seu modo de pensar acerca do uso do dinheiro?", foi respondida por 18 dos participantes. Apesar de ser obrigatória, uma das participantes apresentou uma resposta que não correspondia à pergunta que foi apresentada.

Das respostas validadas, 15 participantes apontaram ter aprendido sobre o modo de pensar acerca do uso do dinheiro em casa. Destes 15 indivíduos, quatro associaram a aprendizagem no lar com outras instâncias: faculdade e/ou mídia e/ou escola. Um dos participantes declarou ter aprendido sobre o uso do dinheiro a partir da mídia e de conversas informais e manipulação de planilhas; duas apresentaram outro caminho para aquisição desse aprendizado: necessidades do dia a dia. É importante destacar que nessa pergunta os participantes poderiam marcar mais de uma alternativa, além de acrescentar outras.

Quando questionados sobre ter tido alguma discussão no Ensino Superior sobre a temática EF, 15 participantes declararam não ter vivenciado tal discussão, enquanto quatro afirmaram que sim. Dentre os que afirmaram ter participado de momentos em que se discutiu a EF, os comentários foram: 1) na aula de financiamento da educação; 2) gasto na família; 3) não me lembro bem, mas acredito que nas aulas de valor monetário. O mercadinho fictício é uma boa maneira de suscitar a temática da Educação Financeira; 4) Nas aulas de Português a professora comentava como ela se organizava financeiramente para poder viajar. Ela dava dicas de Educação Financeira.

Assim, percebemos que os estudantes apontaram de modo vago, não apresentando relação direta com as discussões pertinentes relacionadas à EF. Além disso, destacamos a estudante que aponta a relação entre o Sistema Monetário e a EF, sendo muitas vezes tal relação equivocada. Discutir Sistema Monetário não garante uma discussão efetiva sobre a EF, pois o trabalho com este conteúdo pode ocorrer simplesmente para o reconhecimento de cédulas e moedas ou como pretexto para trabalhar as quatro operações básicas, por exemplo, e para trabalhar a EF é necessário que haja contexto, reflexão, discussão, análise crítica.

Nessa perspectiva, Santos (2017), que analisou livros didáticos de Matemática do Ensino Fundamental anos iniciais, aponta que, apesar de haver muitas atividades nos livros dos alunos discutindo o Sistema Monetário, só foi possível afirmar que tal atividade possuía potencial para discutir a EF a partir da orientação presente no manual do professor, que ampliava as discussões e orientava o docente a discutir aspectos da EF a partir da atividade 
sugerida. Quando não havia tal orientação, a pesquisadora destaca que a atividade não era considerada explicitamente de EF. Assim, uma atividade que envolve Sistema Monetário pode não abarcar discussões que levem os indivíduos a refletir criticamente sobre as relações de consumo. Logo, é preocupante dizer que uma discussão sobre Valor Monetário está contemplando a EF.

Apesar de não possuírem uma maior orientação acerca do uso do dinheiro, de não terem vivenciado no curso de graduação em Pedagogia uma discussão sobre EF e de, em sua maioria (16), não conhecerem a Enef (BRASIL, 2010), 18 dos participantes consideram muito importante a inserção de tal discussão na grade curricular do curso e todos afirmam ser importante discutir a EF em salas de aula da Educação Infantil e/ou dos anos iniciais do Ensino Fundamental. Assim como os indivíduos participantes da pesquisa, Santos (2017) e Silva e Powell (2013) defendem a inserção do trabalho com a EF no ambiente educacional.

Os estudantes, ao serem questionados sobre a importância do trabalho desenvolvido em salas de aula da Educação Básica com a EF, apontam a necessidade de saberem poupar para o futuro, além da organização financeira com os gastos atuais e, ainda, para tornarem-se cidadãos conscientes e críticos, não sendo influenciados pela mídia. Destacam-se os seguintes comentários:

Quadro 1 - Comentários acerca da importância da inserção da EF nas salas de aula da Educação Básica

\begin{tabular}{|c|l|}
\hline Categorias & \multicolumn{1}{|c|}{ Comentários } \\
\hline $\begin{array}{c}\text { Importância de } \\
\text { poupar para o futuro }\end{array}$ & $\begin{array}{l}\text { "Desde criança precisamos saber o que é dinheiro, como investir pensando sempre } \\
\text { no futuro e não no agora ou que "dinheiro foi feito para gastar", sabe?" } \\
\text { "Desta maneira ir iniciando uma maneira correta de poupar." }\end{array}$ \\
\hline $\begin{array}{c}\text { Organização } \\
\text { ginanceira com os } \\
\text { gastos atuais }\end{array}$ & $\begin{array}{l}\text { "Para conscientizar os estudantes da importância de saber administrar seu } \\
\text { "Sim para que os alunos logo cedo tenha responsabilidade de como lidar com o } \\
\text { dinheiro que ele ganha dos pais como por exemplo mesada, como poderá ser gasta, } \\
\text { e economizar para sempre ter algum quando precisar." }\end{array}$ \\
\hline $\begin{array}{c}\text { Construção de } \\
\text { cidadãos críticos e } \\
\text { conscientes }\end{array}$ & $\begin{array}{l}\text { "Aprendendo desde cedo a importância de guardar, saber utilizar esse dinheiro de } \\
\text { mablicitária. } \\
\text { publequada e de maneira consciente indo na contramão da midia }\end{array}$ \\
\hline
\end{tabular}

Fonte: Dados da pesquisa.

Destacamos que os estudantes, ao comentarem sobre a importância de reflexões sobre EF em salas de aula da Educação Básica, remetem-se constantemente ao termo "dinheiro", 
tendendo à ideia equivocada de que para se discutir EF precisa-se necessariamente abordar tal ideia. No presente estudo, defendemos que, para além da discussão sobre o dinheiro, há diversas outras temáticas a serem contempladas e que estão inseridas na discussão sobre a EF. São elas: sustentabilidade, ética, consumo consciente, relacionado ao meio ambiente, querer versus precisar. Nesse sentido, Santos e Assis (2019) ressaltam que a EF não se restringe ao entendimento sobre finanças pessoais, indo além, com discussões como as que contemplam as temáticas acima mencionadas.

Ao serem questionados sobre se sentirem aptos em lecionar acerca da EF, apenas sete participantes afirmam estarem preparados para realizarem tais discussões. Essa afirmação é preocupante, uma vez que estes indivíduos, como destacamos anteriormente, não tiveram formação inicial no curso de Pedagogia que possibilitasse o desenvolvimento de um trabalho efetivo e contínuo com a EF em sala de aula, uma vez que, como já discutido, trabalhar a EF envolve diversas temáticas, com um olhar crítico acerca das situações de consumo.

Diante do exposto, percebemos que há uma lacuna na formação de tais estudantes, uma vez que eles apontam não ter segurança em seus conhecimentos acerca da EF, seja por não terem tido uma vivência familiar que preparasse para lidar criticamente com situações de consumo, seja por não terem tido uma formação profissional que contemplasse tais abordagens.

Destacamos que os participantes da pesquisa estão, ainda, em processo formativo e que podem ter contato com as discussões aqui apresentadas, contudo, uma vez que já cursaram metade ou mais de sua graduação, tendo passado por disciplinas que estão estritamente relacionadas com a $\mathrm{EF}$, entendemos que havia a necessidade de já terem sido imersos nessas discussões.

Desse modo, ressaltamos a importância de que os cursos de formação inicial e continuada, seja no âmbito da Matemática ou de outras áreas, insiram a EF na sua grade curricular, sendo esta uma necessidade também apontada pelos participantes do presente estudo. Além de conhecer sobre se e como a EF está sendo discutida com estudantes de Pedagogia, objetivamos conhecer a prática de professores que trabalham com a EF em suas salas de aula e, por isso, como já afirmado, além de estudantes de Pedagogia, duas professoras, uma de $4^{\circ}$ e uma de $5^{\circ}$ ano do Ensino Fundamental foram participantes deste estudo. A seguir iremos apresentar e discutir sobre a prática destas professoras. 


\section{A prática pedagógica de professores}

Para responder ao nosso segundo objetivo, analisar como professores desenvolvem trabalho com a EF em salas de aula, observamos oito aulas de EF realizadas nas duas turmas em que as professoras pesquisadas atuam, de $4^{\circ}$ e $5^{\circ}$ anos, sendo quatro observações em cada ano de ensino.

É importante destacar que a análise que segue, bem como as que já foram realizadas, não focam em avaliar ou comparar as práticas das professoras, e sim, analisar como as aulas ocorrem para a promoção do trabalho com a EF, ainda que tais profissionais não tenham vivenciado, em seus cursos de formação inicial em Pedagogia discussões sobre a temática EF.

\section{As aulas de Educação Financeira}

Neste tópico apresentamos como ocorreram as observações das aulas de EF da Professora 4 (P4), do $4^{\circ}$ ano e da Professora 5 (P5), do $5^{\circ}$ ano. A dinâmica dos encontros consistia na observação da aula, utilizando como recurso o roteiro de observação e a gravação dos áudios. No início da aula as professoras apresentavam o planejamento de EF do dia, explicando à pesquisadora e aos estudantes da turma o que seria vivenciado naquele dia. Ao término de cada aula, realizamos uma breve entrevista (previamente elaborada e que foi explicitada no método) com as professoras, questionando sobre o alcance dos objetivos, intencionalidade nas atividades, ideias de continuidade do trabalho realizado no dia e avaliação da aula ministrada. No Quadro 2, descrevemos de forma sintética as aulas de EF observadas. É importante destacar que a escola privada onde foi realizada a pesquisa trabalha sistematicamente com a temática como disciplina específica.

Quadro 2 - Descrição das aulas de EF

\begin{tabular}{|c|c|c|}
\hline $\begin{array}{c}\text { Aulas } \\
\text { Observadas }\end{array}$ & Turma do $4^{\circ}$ ano (P4) & Turma do $5^{\circ}$ ano (P5) \\
\hline $1^{\mathrm{a}}$ aula & $\begin{array}{l}\text { O trabalho foi iniciado com a resolução } \\
\text { de atividades do livro didático de } \\
\mathrm{EF}^{3} \text { adotado pela escola, envolvendo o } \\
\text { Sistema Monetário. Em seguida é } \\
\text { pedido para que os alunos destaquem } \\
\text { do material complementar do livro } \\
\text { fichas que representam "dinheirinhos" }\end{array}$ & $\begin{array}{l}\text { P5 distribui os livros didáticos de EF e } \\
\text { realiza uma leitura coletiva de um texto } \\
\text { sobre poupar. Durante toda a leitura são } \\
\text { feitas pausas para discussão dos pontos } \\
\text { do texto. Posteriormente é proposta a } \\
\text { resolução de atividades do livro. }\end{array}$ \\
\hline
\end{tabular}

\footnotetext{
${ }^{3}$ Nas aulas de EF observadas, foram utilizados apenas os livros didáticos de Educação Financeira adotados pela escola, portanto, quando houver pontuações referentes ao livro didático do aluno, estamos nos remetendo ao livro específico de EF adotado.
} 


\begin{tabular}{|c|c|c|}
\hline & $\begin{array}{l}\text { e é proposta por } \mathrm{P} 4 \text { a organização de } \\
\text { uma feirinha com objetos da própria } \\
\text { sala (lápis, caderno, estojo, acessórios } \\
\text { pessoais dos alunos etc.), sendo } \\
\text { realizadas neste momento simulações } \\
\text { de compra e venda desses objetos. }\end{array}$ & \\
\hline $2^{\mathrm{a}}$ aula & $\begin{array}{l}\text { P4 inicia o trabalho com a última } \\
\text { unidade do livro didático de EF - O } \\
\text { poupar. É realizada a leitura coletiva de } \\
\text { um texto do livro e posteriormente a } \\
\text { resolução de atividades também do } \\
\text { livro didático de EF. }\end{array}$ & $\begin{array}{l}\text { P5 relembra alguns conceitos já } \\
\text { trabalhados com a turma como lucro e } \\
\text { prejuízo. Em seguida propõe que os } \\
\text { alunos, em duplas, produzam uma } \\
\text { situação de compra e venda em que haja } \\
\text { troca financeira com lucro e uma } \\
\text { situação com prejuízo. }\end{array}$ \\
\hline $3^{\mathrm{a}}$ aula & $\begin{array}{l}\text { Nesta aula, P4 apresenta uma situação- } \\
\text { problema partindo de um orçamento } \\
\text { fictício presente no livro didático de } \\
\text { EF. Após a resolução do problema, P4 } \\
\text { questiona sobre os sonhos dos alunos e } \\
\text { propõe a definição de sonhos } \\
\text { individuais, discutindo posteriormente } \\
\text { elementos necessários para a } \\
\text { construção de um orçamento para a } \\
\text { realização do sonho. }\end{array}$ & $\begin{array}{l}\text { Esta aula é dedicada às apresentações } \\
\text { das situações de compra e venda } \\
\text { produzidas pelos alunos na aula } \\
\text { anterior. Durante cada apresentação a } \\
\text { professora vai reforçando e discutindo } \\
\text { os conceitos trabalhados com os alunos } \\
\text { (lucro e prejuízo). }\end{array}$ \\
\hline $4^{\mathrm{a}}$ aula & $\begin{array}{l}\text { Esta aula foi continuidade da anterior, } \\
\text { os alunos retomam a produção dos } \\
\text { orçamentos para em seguida apresentá- } \\
\text { los em um grande círculo. }\end{array}$ & $\begin{array}{l}\text { Última aula de EF da turma. Os alunos } \\
\text { abrem o cofrinho em que juntavam, } \\
\text { desde o início do trabalho com a } \\
\text { temática, um ano letivo, dinheiro para a } \\
\text { realização do sonho da turma e contam } \\
\text { quanto pouparam (R\$ 158,00). Em } \\
\text { seguida, eles decidiram o que iriam } \\
\text { realizar com aquela quantia (escolhem } \\
\text { fazer uma manhã de jogos com lanche). }\end{array}$ \\
\hline
\end{tabular}

Fonte: Oliveira (2017).

Diante da sequência de aulas apresentadas, podemos perceber em parte delas (quatro aulas) o uso do livro didático de EF e que este recurso é mais presente na turma da $\mathrm{P} 4$, na qual é utilizado em três das quatro aulas. Por outro lado, também foi visto que P4 e P5 propõem outras atividades que independem do livro didático de EF e esse é um aspecto importante, compreendendo a diversidade de recursos e atividades que podem ser utilizados com o objetivo de desenvolver um trabalho com a temática.

Apresentamos o Quadro 2 com o objetivo de situar de uma maneira geral a sequência das aulas observadas, tendo em vista que na apresentação e discussão que seguem, o foco será dado aos pontos que nos permitem atender aos objetivos do presente estudo. Neste sentido, iremos apresentar e discutir no tópico seguinte a abordagem utilizada pelas professoras 
participantes para o trabalho com a EF e, posteriormente, alguns exemplos de atividades desenvolvidas por elas nas turmas.

\section{Abordagem de EF pelas professoras investigadas}

Neste tópico buscamos responder ao seguinte questionamento: como a EF é trabalhada pelas professoras pesquisadas? Neste sentido, elencamos alguns pontos que orientaram a discussão a seguir. São eles: como é a organização do trabalho com a temática? Quais os temas trabalhados? Quais os recursos utilizados? Como são as atividades desenvolvidas?

Segundo Hofmann (2013, p. 139), para o ensino da EF na escola podem ser utilizadas diferentes abordagens, “[...] pode ser incluído em palestras ou eventos esporádicos, compor uma disciplina específica, pode ser apresentado em diferentes disciplinas".

A escola pesquisada aborda a EF como uma disciplina específica. Nesse sentido, Hofmann (2013, p. 139) discute que "atribuir a um conjunto de conteúdos o espaço curricular de uma disciplina autônoma é, de fato, uma forma categórica de lhe atribuir importância como conhecimento digno de figurar como saber escolar". Embora a escola atribua o status de disciplina à EF, não insere em suas avaliações os conhecimentos desenvolvidos com a temática. Tal dado é apontado por P4 durante a entrevista, ao explicar que em alguns momentos não há a priorização desse trabalho, em relação às outras disciplinas.

$\mathrm{Na}$ disciplina, é dada ênfase a temas como poupança, consumo e investimento, em uma perspectiva de "poupar para consumir", dado evidenciado nas entrevistas com as participantes, no material didático utilizado e nas atividades desenvolvidas em sala. Esses temas são discutidos de maneira pragmática, ou seja, voltados para atividades ou situações do cotidiano próximas ao senso comum. Embora seja realizado um trabalho sistemático com a temática, percebemos que não há tanto aprofundamento nos temas desenvolvidos.

Com relação aos recursos utilizados nas aulas, Hofmann (2013) discute que o material didático pode refletir o potencial de aprofundamento da temática na medida em que o tratamento desse conteúdo seja apenas informativo ou que seja capaz de incitar discussões e reflexões passíveis de se reverterem em mudanças de comportamento. O material didático, que na escola pesquisada refere-se a livros didáticos e paradidáticos para professores e alunos, é voltado para informações gerais sobre os temas e para a resolução de exercícios, que na maioria das vezes, não buscam instigar maiores reflexões, cabendo às professoras realizarem ampliações com o objetivo de refletir sobre a temática. 
É visto nas atividades do livro didático de EF desenvolvidas o estímulo ao consumo. Os enunciados conduzem a isso, por exemplo: "Isabela quer comprar um par de patins..." (p. 62), "Maria Clara estava passeando no shopping quando viu uma boneca incrível...” (p. 63), “o sonho do Eduardo é comprar um violão...” (p. 64). Este dado requer atenção e reflexão por parte do professor e da escola que adota o material. Há um direcionamento para o consumo de bens supérfluos como brinquedos, instrumentos musicais, objetos de lazer, entre outros. Não vimos nas atividades do material (com exceção de uma - Figura 11, Oliveira, 2017, p. 144) contextos que remetessem a um consumo consciente como a compra ou doação de livros, investimento em um curso de informática ou línguas, por exemplo. Assim, haveria ampliação das perspectivas desse consumo para bens necessários e não apenas para o alcance de desejos.

Skovsmose (2014) chama a atenção para o excesso de "bens" que nos cercam, estamos cada dia mais expostos a anúncios, propagandas e precisamos responder a isso de uma forma que não seja aceitando tudo passivamente.

Consumidores são propostos a uma enorme variedade de "bens" (com sua enorme variedade de "males"). Pense em todo tipo de produto: TVs, escovas de dente, cafeteiras, pacotes turísticos e promoções de celular. [...] Como cidadãos, estamos expostos a ações, iniciativas, anúncios, projetos e decisões que fazem parte da matemática em ação. Como cidadãos, teremos de responder a várias formas de matemática em ação, e é possível que façamos isso aceitando tudo cegamente (SKOVSMOSE, 2014, p. 110).

Neste sentido, Resende, Pereira e Kistemann Jr. (2016) defendem a importância da escola como ambiente mobilizador de reflexões, análises e posicionamentos críticos frente a essa demanda de consumo desenfreada.

Problematizar, desde cedo, com os educandos jovens, temáticas relativas ao consumo, formas de se consumir, como lidar com o dinheiro, seja por meio da semanada ou da mesada, vivenciar uma sociedade líquido-moderna com decisões éticas e cidadãs, tem sido as preocupações dos grupos de pesquisas que entendem que a escola pode propiciar em ambientes de investigação que provoquem a gênese de cidadãos de fato, e que esses cidadãos ajam, tomando decisões autônomas e críticas a partir de suas análises das propagandas e das estratégias de marketing (RESENDE; PEREIRA; KISTEMANN JR, 2016, pp. 99-100 - grifo nosso).

Com as professoras investigadas, há no trabalho com a temática um claro direcionamento a partir do livro didático. Essa percepção é mais presente nas aulas de P4, que, como afirmado anteriormente, utiliza o material em três das quatro aulas observadas em sua turma. Apesar disso, consideramos importante destacar que no decorrer das aulas houve 
momentos de extrapolação que foram materializados pela construção de novas atividades pelas próprias professoras, envolvendo contextos de tomada de decisão, sustentabilidade, consumo consciente e inconsciente, que são pertinentes para o trabalho com a EF.

Dados os expostos, afirmamos que a EF é trabalhada, pelas professoras investigadas, de modo geral, em uma perspectiva voltada para os conhecimentos econômico-financeiros, ou seja, orientações sobre como obter, usar e poupar dinheiro. Acreditamos que tal fato explicase, fortemente, pelo material adotado pela escola para o trabalho com a EF.

Em consonância, Muniz (2016, p. 22) aponta que

Considerando que uma EFE não deve propor apenas um conjunto de orientações sobre como obter, usar, distribuir e poupar dinheiro e, portanto, um conjunto de orientações econômico-financeiras, mas deve ser um convite à reflexão sobre diversos aspectos da sociedade envolvidos nas escolhas envolvendo o dinheiro e suas consequências, temos que a tomada de decisão é uma das principais ações na direção de uma cidadania crítica que saiba avaliar esses diversos aspectos.

Embora o material proponha uma perspectiva restrita, é visto por parte das professoras, em determinados momentos, um esforço em realizar um trabalho com a EF partindo da reflexão na tomada de decisão, da ampliação de atividades sem ficar restrita apenas ao livro (mesmo que isso aconteça em maior intensidade na prática de P5), a discussão de temas que extrapolam o poupar e o consumo de bens supérfluos, como o consumo consciente de energia elétrica, a compreensão do querer versus precisar, o respeito ao sonho do outro, os significados construídos pelos alunos na tomada de decisão sobre as situações de lucro e prejuízo, na escolha de um sonho coletivo tendo um orçamento relativamente curto, entre outras discussões que P4 e P5 propuseram a partir de seus entendimentos e importância dada à temática.

Resultado importante, no presente estudo, é o papel fundamental do professor para o trabalho com EF, na compreensão e enfrentamento dos desafios trazidos com a inserção da temática. Desafios de superar uma formação insuficiente, que não contempla a temática em um viés educacional, apenas econômico; desafios de promover espaços de reflexões sobre a tomada de decisão, compreendendo os aspectos que as influenciam; desafios de validar estes conhecimentos como saberes escolares e necessários para a construção de uma cidadania crítica e na promoção de escolhas mais conscientes frente às situações financeiras vivenciadas por cada indivíduo, independente de classe social.

Com as professoras investigadas, apesar de haver um contexto que favorecesse a EF na perspectiva do "poupe hoje para comprar amanhã", houve o extrapolamento das discussões, 
com reflexões mais críticas e reflexivas. Apesar disso, como garantir que os estudantes de Pedagogia em formação, sem formação adequada acerca da temática, atuem da mesma forma em sala de aula? É possível que alguns deles fiquem "bitolados" à discussão posta no material, deixando de trabalhar importantes temáticas relacionadas à EF com os seus estudantes. Por isso, fazemos a defesa de que tal temática precisa ser discutida nos cursos de formação inicial e continuada, possibilitando aos docentes mais subsídios para o desenvolvimento do tema em sua amplitude, em sala de aula.

\section{Atividades de EF desenvolvidas pelas professoras investigadas}

No Quadro 3, a seguir, apresentamos as atividades desenvolvidas para o trabalho com a EF pelas professoras investigadas.

Quadro 3 - Atividades desenvolvidas pelas professoras pesquisadas nas aulas de EF

\begin{tabular}{|l|l|l|}
\hline \multicolumn{1}{|c|}{ Atividades realizadas } & \multicolumn{1}{|c|}{$\mathbf{4}^{\mathbf{0}}$ ano (P4) } & \multicolumn{1}{c|}{$\mathbf{5}^{\mathbf{0}}$ ano (P5) } \\
\hline Resolução de problemas em livro didático de EF & Aulas $(1,2,3)^{4}$ & Aula (1) \\
\hline Simulação de feirinha & Aula (1) & - \\
\hline Produção e discussão de situações de compra e venda & - & Aula (2,3) \\
\hline Criação de orçamento individual & Aula (3,4) & - \\
\hline Leitura e reflexão de texto sobre poupar & Aula (2) & Aula (1) \\
\hline Definição de sonho coletivo & - & Aula (4) \\
\hline
\end{tabular}

Fonte: Oliveira (2017).

A partir do Quadro 3, podemos perceber que a resolução de problemas em livro didático de EF apresenta maior frequência nas aulas, sendo trabalhada em quatro delas. Percebemos também que as atividades de leitura de texto sobre poupar e resoluções de problemas no livro estão presentes em duas aulas de cada turma, ou seja, a organização para o trabalho entre as professoras se mostra bem semelhante no que concerne à disposição das aulas, porém, em relação às conduções, percebemos algumas diferenças. Ainda sobre a organização das aulas, de

\footnotetext{
${ }^{4}$ É importante pontuarmos que as atividades do livro didático (resolução de problemas) contemplaram nas aulas 1 e 3 de P4 apenas parte da aula, sendo utilizada a outra parte para a realização de atividades como a simulação de feirinha (aula 1) e a criação de orçamento individual (aula 2), por isso a repetição de mais de um tipo de atividade por aula.
} 
um modo geral, tudo que estava no planejamento foi contemplado, no entanto, a execução sempre extrapolava o planejamento e, ao avaliar a aula ou as atividades nas entrevistas pósaulas, quase sempre as professoras propuseram ampliações no sentido de enriquecer o trabalho. Tais aspectos são comuns quando se compreende a flexibilidade e a reflexão da prática pedagógica como elementos inerentes ao planejamento. As diferenças durante a condução e as pontuações das professoras frente às atividades serão apresentadas ao longo das discussões. A seguir, iremos descrever e analisar algumas das atividades desenvolvidas nas aulas.

\section{Atividades do livro didático de EF}

Foram trabalhadas 15 atividades do livro didático de EF no decorrer das aulas observadas. Destas 15 atividades desenvolvidas, consideramos que apenas oito envolviam o trabalho com a EF. As atividades não consideradas de EF foram aquelas que não possibilitavam sozinhas nenhuma reflexão sobre a temática, envolvendo apenas contextos matemáticos e que, durante a prática das professoras, não houve discussões que desencadeassem este trabalho. Algumas das atividades foram consideradas de EF partindo dos encaminhamentos dados pelas participantes no desenvolvimento da atividade, pois a atividade sozinha não levava a discussões sobre o trabalho com a temática.

É importante chamar a atenção sobre um aspecto destas atividades, elas fazem parte de livros específicos de EF organizados para este trabalho, portanto, é preocupante encontrar atividades que envolvam apenas a resolução de problemas contendo o Sistema Monetário, por exemplo, sem instigar nenhuma reflexão sobre a temática.

De modo geral, as atividades que não contemplavam o trabalho com a EF envolviam, além de contextos com o Sistema Monetário, empreendedorismo e situações com contextos de compra e venda com foco apenas no trabalho com conteúdos matemáticos como números decimais, adição, divisão. Desse modo, eram utilizados como pretexto, por exemplo, a pesquisa em folhetos de supermercado apenas para identificar quais produtos poderiam ser comprados com determinado valor.

Esta atividade trabalha o uso do Sistema Monetário em um contexto de compras, no qual é pedido que os alunos pesquisem em folhetos de supermercado produtos utilizados por eles e suas famílias que correspondam aos valores determinados na atividade, a qual foi orientada como tarefa para casa e apenas corrigida por P4 de maneira individual. Esta atividade não foi considerada de $\mathrm{EF}$, pois por si só não remete a nenhuma discussão com a temática, envolvendo apenas a identificação de produtos com os valores apresentados. Contudo, 
dependendo dos encaminhamentos adotados por P4, esta situação poderia contemplar discussões como economia doméstica, custo e benefício, influências de propagandas no momento da compra, entre outras, que são refletidas no trabalho com a EF.

Outro exemplo de atividade que teria potencial para o trabalho com a EF é vista na Figura 1.

Figura 1 - Exemplo de atividade envolvendo cálculo

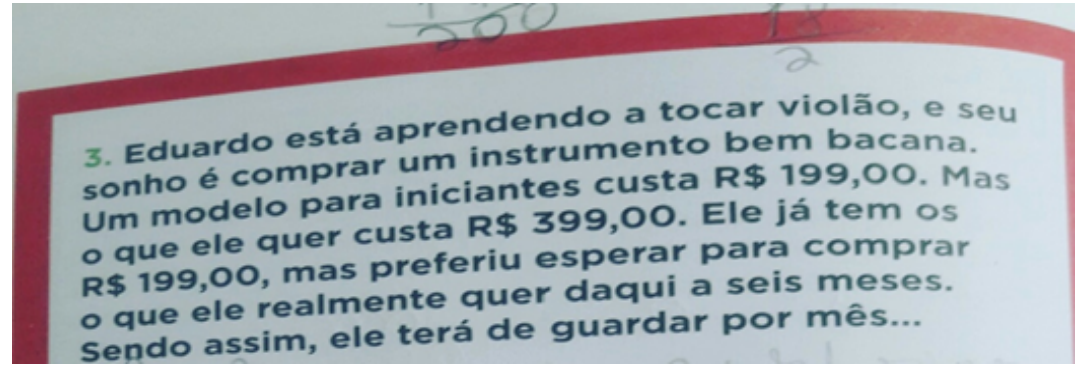

Fonte: Domingos (2012, p. $64-4^{\mathrm{o}}$ ano).

Nela, era apresentado um contexto de economia para a realização de um sonho, um instrumento musical de Eduardo (personagem fictício). Na situação, Eduardo não possuía o valor total para comprar o instrumento que ele queria, mas que daria para comprar outro, mais barato. Porém, ele decidiu esperar seis meses até conseguir o valor total do produto desejado (DOMINGOS, 2012, p. 64, $4^{\circ}$ ano). Esta situação, se refletida por P4, poderia gerar discussões sobre a tomada de decisão, pois embora ele pudesse comprar um produto mais barato, resolveu esperar. Também poderiam ser discutidas ideias sobre o imediatismo na hora das compras, que muitas vezes leva a um consumo inconsciente. Outra discussão que poderia ser gerada é sobre o desejo versus a necessidade, pois se de fato o produto da compra fosse um bem para sobrevivência, ele poderia esperar para comprar o produto ou teria que comprar o que o dinheiro possibilitasse no momento?

Ao propor esta atividade, a professora realizou com os alunos apenas o que está sugerido no final do enunciado, um cálculo numérico. No cálculo, P4 exemplifica uma das possibilidades de resposta, na qual foi realizada uma subtração para saber quanto faltava para Eduardo completar o dinheiro (399-199 = 200 reais) e posteriormente uma divisão desse valor pela quantidade de meses que seriam esperados (200:6 $=33,33$ reais $)$.

Consideramos que, embora a atividade sozinha não promova ou induza a algum tipo de reflexão sobre EF, o professor em sua prática de sala de aula pode e deve ultrapassar orientações que limitam ou por vezes inviabilizam o trabalho com a EF. No entanto, compreendemos que 
a falta de conhecimento ou formação insuficiente possam influenciar o desempenho do professor frente ao desenvolvimento do trabalho com a EF.

\section{Considerações Finais}

Tivemos como objetivos deste estudo investigar se e como a EF está sendo discutida em cursos de formação inicial de professores dos anos iniciais e analisar como professores desenvolvem trabalho com tal temática em salas de aula. $\mathrm{O}$ estudo foi desenvolvido com a participação de 19 estudantes do ensino superior em Pedagogia que já haviam cursado, pelo menos, a metade do curso, bem como de duas docentes dos $4^{\circ}$ e $5^{\circ}$ anos do Ensino Fundamental. O estudo, apesar de desenvolvido com um grupo específico de participantes, aponta importantes reflexões para a EF e a formação de professores dos anos iniciais do Ensino Fundamental, como apontamos a seguir.

A partir dos achados, pudemos constatar que os alunos que estão em processo de formação percebem a importância de tal temática ser trabalhada em salas de aula nas escolas, apesar de, de acordo com os relatos, não terem, em sua maioria, participado sistematicamente de discussões acerca do tema em suas formações.

Os estudantes apontam, ainda, que um trabalho sistemático com EF no ambiente escolar pode favorecer uma organização financeira atual e para o futuro para esses alunos, além de formarem cidadãos críticos e de opinião, não deixando serem manipulados pela mídia. Ainda podemos destacar que, apesar de defenderem a inclusão da EF no currículo escolar, 16 deles não se sentem seguros quanto aos seus conhecimentos acerca do gerenciamento do dinheiro. Além disso, 12 dos estudantes investigados afirmam não se sentirem seguros para abordar a EF em suas futuras salas de aula, levando em consideração o nível de conhecimento que possuíam no momento da realização da pesquisa.

Ressaltamos, ainda, que, em quase totalidade, os estudantes participantes da pesquisa, acreditam que a EF deve ser um tema que deva adentrar no currículo do curso de formação inicial de professores, a fim de garantirem um aproveitamento para possíveis links com a EFE. Nesta perspectiva, Silva (2016) reforça a necessidade de haver tal inserção, seja na formação inicial ou continuada dos docentes.

No que se refere às professoras investigadas, que atuam em salas de aula dos anos iniciais do Ensino Fundamental e não receberam formação inicial sobre EF, destacamos que as docentes apresentam tentativas de ampliação da discussão, favorecendo discussões que iam além do que estava posto no material adotado pela escola para o trabalho com a temática. Apesar 
disso, em determinados momentos, acreditamos que, por falta de formação sobre o tema, as professoras se detinham ao que estava apresentado no material estruturado, com discussões que não favoreciam aos estudantes o potencial crítico e reflexivo que a EF possui.

Diante do exposto, defendemos a necessidade de haver uma inclusão, nos cursos de formação de professores dos anos iniciais, de discussões acerca da EF, e que, ainda, tais abordagens extrapolem a ideia da Matemática, aparecendo, também, sistematicamente, em outras disciplinas ofertadas na grade curricular do curso, uma vez que, atualmente, a EF faz parte, de forma consciente e clara, da nossa sociedade como um todo e precisa ser vista em suas diversas facetas. Destacamos também a necessidade de formações continuadas, de modo a atender aos docentes que são atuantes em sala de aula, mas não participaram de discussões sobre esse tema em seus cursos de formação inicial.

\section{Referências}

BALL, D. L.; THAMES, M. H.; PHELPS, G. Content Knowledge for Teaching: what makes it special? Journal of teacher education. v. 59, n. 5, pp. 389-407, 2008.

BRASIL. Decreto $\mathbf{n}^{\mathbf{0}} \mathbf{7 . 3 9 7}$ de 2010. BRASIL: Implementando a Estratégia Nacional de Educação Financeira, Brasília, 2010.

BRASIL. Ministério da Educação. Secretaria da Educação Básica. Base Nacional Comum Curricular. Brasília, DF, 2017. Disponível em: http://basenacionalcomum.mec.gov.br/wpcontent/uploads/2018/02/bncc-20dez-site.pdf. Acesso em: 19 ago. 2018.

CAMPOS, A.; KISTEMANN JR, M. A. Atividades e reflexões sobre planejamento financeiro, orçamento e economia doméstica. Produto Educacional. Programa de Mestrado Profissional em Educação Matemática. Minas Gerais, 2015.

CAMPOS, M. Educação Financeira na Matemática do Ensino Fundamental: uma análise da produção de significados. 2012. Dissertação (Mestrado) - Programa de Mestrado Profissional em Educação Matemática, Minas Gerais, 2012.

COSTA, J.; PINHEIRO, N.; COSTA, E. A formação para matemática do professor de anos iniciais. Ciência e Educação, Bauru, v. 22, n. 2, 2016.

CUNHA, D. R. A matemática na formação de professores dos anos iniciais do ensino fundamental: relações entre a formação inicial e a prática pedagógica. 2010. $107 \mathrm{f}$. Dissertação (Mestrado) - Faculdade de Física, Pontifícia Universidade Católica do Rio Grande do Sul, Porto Alegre, 2010.

CURI, E. A Matemática e os professores dos anos iniciais. São Paulo: Ed. Musa, 2005. 
CURI, E.; PIRES, C. A formação Matemática de professores dos anos iniciais do ensino fundamental face às novas demandas. Anais do VIII Encontro Nacional de Educação Matemática - VIII ENEM. Recife, 2004.

DOMINGOS, Reinaldo. Coleção DSOP de educação financeira, $4^{\circ}$ ano: Ensino Fundamental. São Paulo, DSOP Educação Financeira, 2012.

HOFMANN, R. Educação financeira no currículo escolar: uma análise comparativa das iniciativas da Inglaterra e da França. 2013. Tese (Doutorado) - Pós-graduação em Educação da Universidade Federal do Paraná, Curitiba, 2013.

KASSARDJIAN, A. Educação Financeira Infantil: como o incentivo a essa prática pode auxiliar na formação de adultos financeiramente mais conscientes. 2013. Dissertação (Mestrado) - Escola de Administração de Empresas de São Paulo da Fundação Getúlio Vargas, São Paulo, 2013.

MUNIZ, I. Econs ou Humanos? Um estudo sobre a tomada de decisão em ambientes de Educação Financeira Escolar. 2016. Tese (Doutorado) - Pós-graduação em Engenharia de Produção, COPPE, da Universidade Federal do Rio de Janeiro, Rio de Janeiro, 2016.

NACARATO, A. M. Educação continuada sob a perspectiva da pesquisa-ação: currículo em ação de um grupo de professoras ao aprender ensinando Geometria. 2000. Tese (Doutorado em Educação) - Faculdade de Educação, Unicamp, Campinas, 2000.

OLIVEIRA, A. Educação Financeira nos anos iniciais do Ensino Fundamental: como tem ocorrido na sala de aula? 2017. Dissertação (Mestrado) - Universidade Federal de Pernambuco, Recife, 2017.

PELICIOLI, A. F. A relevância da educação financeira na formação de jovens. 2011. Dissertação (Mestrado em Educação em Ciências e Matemática) - Faculdade de Física, PUCRS, Porto Alegre, 2011.

RESENDE, A.; PEREIRA, C.; KISTEMANN JR, M. Sobre Educação Matemática, Publicidade e Consumismo Infantil. Boletim do LABEM, v. 7, n. 13, ago. /dez. de 2016.

ROCHA, C. Formação docente e o ensino de problemas combinatórios: diversos olhares, diferentes conhecimentos. 2011. Dissertação (Mestrado em Educação Matemática e Tecnológica) - UFPE, Recife, 2011.

SANTOS, L. Educação Financeira em livros didáticos de Matemática dos anos iniciais do Ensino Fundamental: quais as atividades sugeridas nos livros dos alunos e as orientações presentes nos manuais dos professores? 2017. Dissertação (Mestrado) - Universidade Federal de Pernambuco, Recife, 2017. 
SANTOS, L.; ASSIS, A. A Educação Financeira na formação inicial de professores que ensinam Matemática nos anos iniciais do Ensino Fundamental: como está acontecendo? Anais do XIII Encontro Nacional de Educação Matemática - XIII ENEM. Cuiabá, 2019.

SILVA, A. Uma proposta de formação continuada de professores em Educação Financeira Escolar. Anais do XII Encontro Nacional de Educação Matemática - XII ENEM. São Paulo, 2016.

SILVA, A. Atividades de Educação Financeira em livro didático de Matemática: como os professores colocam em prática? 2018. Dissertação (Mestrado) - Universidade Federal de Pernambuco, Recife, 2018.

SILVA, A.; POWELL, A. Um programa de Educação Financeira para a Matemática escolar da Educação Básica. Anais do XI Encontro Nacional de Educação Matemática - XI ENEM. Curitiba, 2013.

SKOVSMOSE, O. Um convite à educação matemática crítica. Campinas, SP: Papirus, 2014.

TEIXEIRA, D. Educação Financeira no Ensino Fundamental: conhecimentos identificados em um grupo de professores do quinto ano. 2017. Dissertação (Mestrado) - Pontifícia Universidade Católica de São Paulo, São Paulo, 2017.

VASCONCELLOS, M.; BITTAR, M. A formação do professor para o ensino de Matemática na educação infantil e nos anos iniciais: uma análise da produção dos eventos da área.

Educação Matemática Pesquisa, São Paulo, v. 9, n. 2, pp. 275-292, 2007. 